\title{
Geographic origin of the Y Chromosomes in "old" inbred strains of mice
}

\author{
Priscilla K. Tucker, ${ }^{1,2}$ Barbara K. Lee, ${ }^{1}$ Barbara L. Lundrigan, ${ }^{2}$ and Eva M. Eicher ${ }^{1}$ \\ ${ }^{1}$ The Jackson Laboratory, Bar Harbor, Maine 04609, USA; ${ }^{2}$ The Museum of Zoology and Department of Biology, University of \\ Michigan, Ann Arbor, Michigan 48109, USA
}

Received December 17, 1991; accepted March 20, 1992

\begin{abstract}
Six distinct Y Chromosomes (Chr) were identified among 39 standard inbred strains of mice with five probes that identified Y Chr-specific restriction fragments on Southern blots. Three Y Chr types, distributed among 31 strains, were of Asian Mus musculus origin. The remaining three Y Chr types, distributed among eight strains, were of $M$. domesticus origin. The Asian source of the M. musculus $\mathrm{Y}$ Chr was confirmed by determining the DNA sequence of 221 bp from an open reading frame within the Sry (sex determining region $\mathrm{Y}$ ) gene (Gubbay et al., Nature 346: $245-250,1990)$ in three inbred strains $(\mathrm{C} 57 \mathrm{BL} / 6 \mathrm{~J}$, $\mathrm{AKR} / \mathrm{J}$, and $\mathrm{SWR} / \mathrm{J}$ ) and comparing the sequence to the homologous sequences derived from wild caught European and Asian $M$. musculus males. These data indicate that a minimum of six male mice contributed to the formation of the old inbred strains.
\end{abstract}

\section{Introduction}

The "old" inbred strains of the laboratory mouse are known to be derived from the rodent species complex Mus musculus (Family Muridae, subfamily Murinae). This cosmopolitan species complex is composed of numerous geographically isolated populations displaying considerable genetic differentiation and identified as either distinct subspecies or species (reviewed in Bonhomme 1986; Moriwaki et al. 1986). Bonhomme and co-workers recognize four biochemically defined subspecies of Mus musculus (Bonhomme et al. 1986): Mus musculus domesticus, which is distributed throughout Western Europe, the Mediterranean basin, Africa, and the Middle East, and has been introduced by man to other continents; M.m. bactrianus, which ranges from Iran to Pakistan and India; M.m. castaneus, which

Offprint requests to: P.K. Tucker, at Michigan address ranges from Ceylon to South East Asia; and M.m. musculus, which ranges from Eastern Europe, across northern Asia, to Japan. M.m. molossinus from Japan, an additional subspecies frequently mentioned in the literature, is actually a mixture of Asian M.m. musculus, M.m. castaneus, and M.m. domesticus genomes (Yonekawa et al. 1986, 1988; Bonhomme et al. 1989). (For convenience we refer to samples of $M$. musculus from Japan as M.m. molossinus.) The classification system of Bonhomme and co-workers is generally accepted except for M.m. domesticus, which is considered by some to be a separate species.

Species designation is justified because European populations of $M$. domesticus and M.m. musculus hybridize only restrictively in a narrow zone of overlap (Hunt and Selander 1973; Ferris et al. 1983b; Vanlerberghe et al. 1986, 1988a, 1988b; Sage et al. 1986a, 1986b; Tucker et al. 1992). For this reason we hereafter refer to M.m. domesticus as M.domesticus.

Although the genealogical history of many of the "old" inbred strains is documented (reviewed in Morse 1978; Atchley and Fitch 1991), information regarding the relationship of the founding individuals to their wild ancestors is not recorded. It is believed that mice from Japan contributed to the formation of the "old" inbred strains by way of the mouse fanciers' trade (Keeler 1931; Potter 1978; Festing and Lovell 1981). This is in accord with biochemical data suggesting that Japanese M.m. musculus (M.m. molossinus) and $M . m$. castaneus both contributed to the formation of inbred strains (Blank et al. 1986).

During the past decade, the origins of inbred mouse strains have been investigated by use of restriction fragment length polymorphism (RFLP) studies of two clonally inherited molecules, maternally inherited mitochondrial DNA (mtDNA) and paternally inherited Y Chr-specific DNA (Yonekawa et al. 1980, 1982; Ferris et al. 1982, 1983a; Bishop et al. 1985; Nishioka and Lamothe 1986; Nishioka 1987). The majority of the “old' inbred strains carry $M$. domesticus mtDNA and 
an $M$. musculus $\mathrm{Y}$ Chr, while a smaller number carry $M$. domesticus mtDNA and an $M$. domesticus $\mathrm{Y}$ Chr. Because the $\mathrm{Y}$-specific probes used in these studies could not distinguish between Asian- and Europeanderived $M$. musculus Y Chrs, it was unclear whether the $M$. musculus $\mathrm{Y} \mathrm{Chr}$ of the inbred strains was of Asian or Eastern European origin.

We previously reported that the Y-specific probe pYB10 could identify different Y Chrs among populations of $M$. musculus and $M$. domesticus mice and, in particular, could differentiate between $M$. musculus $\mathrm{Y}$ Chrs of Asian and Eastern European origin (Tucker et al. 1989). We have extended this study to determine the $\mathrm{Y}$ chromosomal origin of 39 inbred strains of mice.

\section{Materials and methods}

\section{Mice}

Pedigreed pairs of mice from the following inbred strains and sublines were obtained from either the Foundation or Research colonies of The Jackson Laboratory and are listed in Table 1. Wild mice used in this study were either field-caught or were obtained from established laboratory colonies. Original collecting localities for fieldcaught mice and wild mice obtained from laboratory colonies are given in Tucker and co-workers (1989). Thirty inbred strains were

Table 1. Summary table of the six types of $\mathrm{Y}$ Chrs among inbred strains identified using three distinct hybridization probes. In some cases more than one subline (identified by indentation) of an inbred strain was examined.

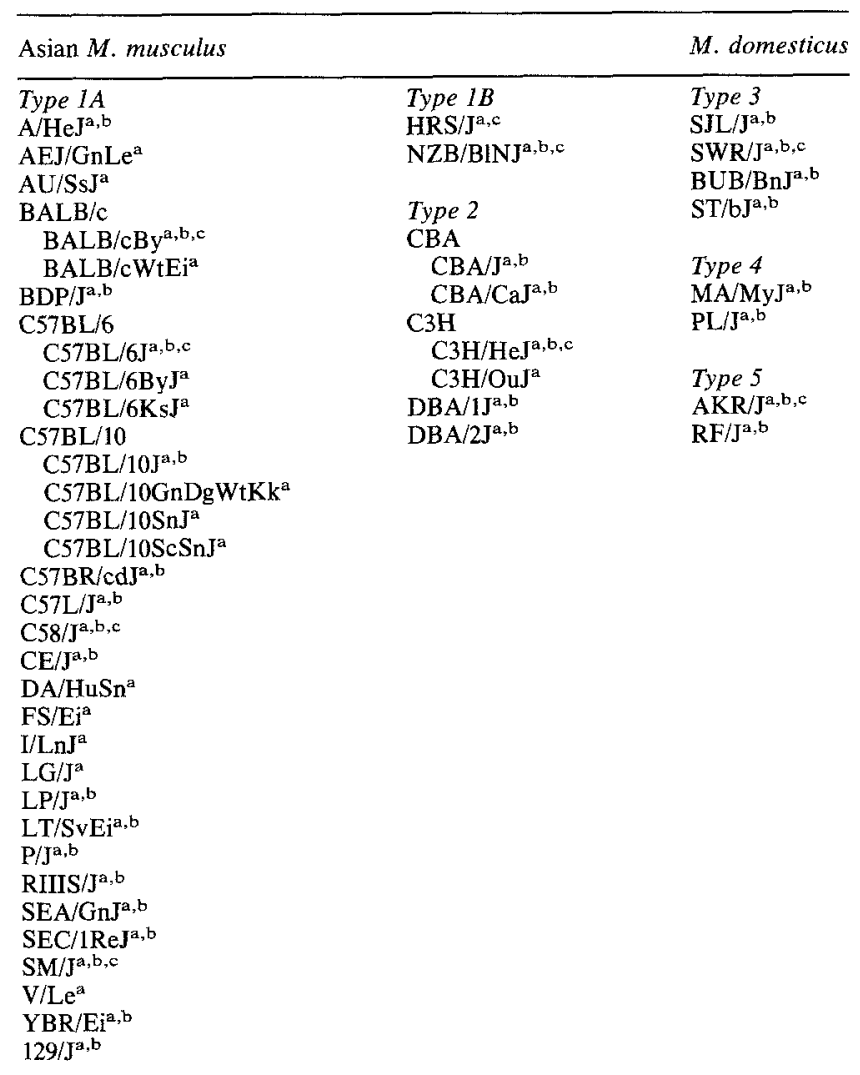

\footnotetext{
${ }^{a}$ Inbred strains probed with pXenv and pMo-MCFenv

b Inbred strains probed with pYB10.

${ }^{c}$ Inbred strains probed with $\mathrm{XENO}_{112}$ and $\mathrm{MCF}_{100}$.
}

used in the pYB10 analysis. An additional nine strains for a total of 39 strains were used in the pXenv and pMo-MCFenv analyses. Nine strains (of the 39 sampled) were used in the $\mathrm{XENO}_{112}$ and $\mathrm{MCF}_{100}$ analysis (see footnote in Table 1).

\section{Hybridization probes and radiolabeling}

Five probes were used: (1) pYB10 (EMBL accession \#X12900), a 305 -bp EcoRI-PstI anonymous sequence that detects multiple copy sequences on the $\mathrm{Y} \mathrm{Chr}$ of $\mathrm{C} 57 \mathrm{BL} / 10$ and on the $\mathrm{Y} \mathrm{Chr}$ of five species in the genus Mus (Eicher et al. 1989); (2) pXenv, a 455-bp $B g I I I-E c o$ RI env-specific sequence of NSF-Th-1 xenotropic MLV proviral DNA (Buckler et al. 1982); (3) pMo-MCFenv, a 622-bp $B a m H I-E c o$ RI $e n v$-specific sequence of the Moloney-MCF virus (Bosselman et al. 1982); (4) $\mathrm{XENO}_{112}$, a unique 112-bp xenotropic $e n v$-specific sequence isolated from the NZB-IU-6 virus; and (5) $\mathrm{MCF}_{100}$, a 100-bp of unique (mink cell focus-forming) env-specific sequence ( $O$ 'Neill et al. 1986). Probes were labeled to a specific activity of $0.5 \times 10^{9} \mathrm{cpm} / \mu \mathrm{g}(\mathrm{pYB} 10)$ or $1 \times 10^{9} \mathrm{cpm} / \mu \mathrm{g}$ (pXenv and pMo-MCFenv) with $\alpha^{-32} \mathrm{P}$-dCTP (Amersham) according to Maniatis and colleagues (1982) and with the $\mathrm{T}_{4}$ polymerase kit supplied by $\mathrm{BRL}$. The $\mathrm{XENO}_{112}$ and $\mathrm{MCF}_{100}$ probes were labeled according to a modification of the M13 dideoxy sequencing method previously described (Eicher et al. 1989).

\section{Restriction endonuclease digestions and Southern blot analyses}

Five restriction enzymes, including one four-base cutter $(T a q I)$ and four six-base cutters (BglII, EcoRI, $P v u I I, P s t \mathrm{I})$, were used in the analysis of pYB10. One restriction enzyme $(B g l \mathrm{II})$ was used in the analysis of pXenv, pMo-MCFenv, XENO ${ }_{112}$, and $\mathrm{MCF}_{100}$. Restriction endonuclease digestions, Southern blot preparations, hybridization conditions, and autoradiography were performed as described by Tucker and co-workers (1989).

\section{Analysis of autoradiographs and phylogenetic analysis}

The approximate size of each YB10 restriction fragment was ascertained. Fragments of indistinguishable size generated by the same restriction enzyme were assumed to be identical between taxa, and each taxon was scored for presence or absence of each restriction fragment identified. The restriction fragments were used as characters in a phylogenetic analysis by use of parsimony (PAUP, version 2.4; Swofford 1985). Variation in copy number among equal-sized restriction fragments was not scored as a separate character. The use of a multiple copy DNA sequence for phylogenetic analyses presents a methodological problem because restriction fragments of a repeated sequence cannot be mapped to specific sites, and thus it is impossible to determine whether the presence or absence of each restriction fragment represents an independent evolutionary event. Despite this problem, previous analyses have demonstrated that the YB10 repeat is phylogenetically informative (Tucker et al. 1989). Sizes of Y-specific restriction fragments also were determined for each of the nonecotropic viral probes, but were not included in the phylogenetic analysis.

\section{$P C R$ amplification and sequencing of an Sry open reading frame}

Two oligonucleotide primers (5' AGATCTTGATTTTTAGTGTTC $3^{\prime}$ and $5^{\prime}$ GAGTACAGGTGTGCAGCTCTA $3^{\prime}$ ) were used to enzymatically amplify a 471-bp fragment from the $S r y$ locus (Gubbay et al. 1990) following Saiki and colleagues (1985) and the protocol of Perkin-Elmer Cetus, except that only one-half of the recommended concentration of each $10-\mu \mathrm{M}$ primer was used. Controls consisted of primers, dNTPs, buffer, and Taq polymerase, but no template DNA. Double-stranded products were separated on a $3 \%$ Nusieve 
gel, stained with ethidium bromide, and visualized under UV light. To verify that amplified sequences were $Y$ specific, preliminary amplification experiments included both male and female genomic DNA from each inbred strain and subspecies under investigation. Amplification of the target size sequence (the 471 bp open reading frame) in males only was taken as evidence that the sequence was $Y$-specific.

Double-stranded products were purified by centrifugation dialysis as described by Allard and co-workers (1991). Purified doublestranded products were dried under vacuum and resuspended in 15 $\mu 1$ of $1 \times$ TE. Single-stranded DNA was amplified from $2 \mu$ of the double-stranded product by use of the reaction conditions for the double-stranded amplification, except that only the $5^{t}$ primer was included. Single-stranded sequences were visualized and purified by the procedure described for double-stranded products. Purified single-stranded products were dried under vacuum and resuspended in $15 \mu 1$ of $1 \times$ TE buffer. Half of the purified single-stranded product was sequenced by the Sanger dideoxy sequencing technique (Sanger et al. 1977) and the Sequenase Version 2.0 sequencing kit (United States Biochemical) according to the manufacturer's recommendations.

\section{Sry sequence analysis}

Sequences were aligned (Altschul and Ericson 1986) with the published sequence from the 129 inbred strain (Gubbay et al. 1990). Aligned sequences were inspected for nucleotide substitutions.

\section{Results}

\section{RFLP analysis with $p Y B 10$}

Five distinct YB10 hybridization patterns identifying Y Chr types 1 through 5 (Table 1) were detected on Southern blots containing male genomic DNA from 30 inbred mouse strains (Table 2, Fig. 1). Representatives of these five patterns were included in a phylogenetic analysis (PAUP, version 2.4; Swofford 1985) along with 25 samples from geographically distinct populations of $M$. musculus and $M$. domesticus, and one sample of $M$. spicilegus. (M. spicilegus is considered a sister taxa to $M$. domesticus and $M$. musculus and thus served as the outgroup). In total, 123 restriction fragments generated from single digests were used as characters, and 25 most parsimonious trees were found in a heuristic search. In all 25 trees the relationship of inbred strains to wild-caught $M$. domesticus, M.m. molossinus, European M.m. musculus, and M.m. castaneus were identical (Fig. 2). The two types of inbred strains represented by C57BL/6J (type 1) and CBA/J (type 2) were most closely related to $M . m$. molossinus, and the three classes of inbred strains represented by SWR/J (type 3), AKR/J (type 5), and MA/MyJ (type 4) were most closely related to $M$. domesticus. The inbred strains represented by SWR/J were most closely related to $M$. domesticus collected in Germany; the inbred strains represented by $A K R / J$ and MA/MyJ were most closely related to $M$. domesticus collected in Maryland.

\section{RFLP analysis with nonecotropic virus probes}

Four distinct male-specific hybridization patterns were observed when $B g l \mathrm{II}$-digested DNA from males and females of 39 inbred strains was hybridized with the nonecotropic virus probes pXenv and pMo-MCFenv. The eight inbred strains identified as having a $M$. domesticus Y Chr with pYB10 (types 3, 4, and 5, Table 1) contained no BglII male-specific proviral fragments. The remaining 31 strains, including the 22 inbred strains identified as having an $M$. musculus Y Chr with pYB10, were divided into three types (Table 1): type 1A contained a $7.8,6.0$, and $4.6 \mathrm{~kb}$ $B g l$ II male-specific fragment; type $1 \mathrm{~B}$ contained the 7.8 and $4.6 \mathrm{~kb}$ Bglll male-specific fragments; and type 2 contained only the $4.6 \mathrm{~kb} \mathrm{BglII}$ male-specific fragment. Because pXenv and pMo-MCFenv do not distinguish xenotropic from MCF proviral sequences, further analysis was performed with $\mathrm{pXENO}_{112}$, a xeno-specific probe, and $\mathrm{pMCF}_{100}$, an $\mathrm{MCF}$-specific sequence on DNA from females and males of nine inbred strains (see Table 1), representing each of the previously identified types. Male-specific patterns of hybridization identical to those observed with the $\mathrm{pX}$ env and pMo-MCFenv were observed only with $\mathrm{pX}$ $\mathrm{ENO}_{112}$; no male-specific $B g l I I$ fragments were identified with $\mathrm{pMCF}_{100}$, indicating that the proviral sequences located on these M.m. musculus Y Chrs are xenotropic in origin.

\section{Sequence analysis of the Sry open reading frame}

The nucleotide sequence of $221 \mathrm{bp}$ (positions 162-383) of the 471 bp open reading frame from $S r y$ was determined for three inbred strains (SWR/J, AKR/J, and C57BL/6J), two M.m. musculus males from Europe (Skive, Denmark; and Sladeckovce, Czechoslovakia), one M.m. molossinus male from Asia (Kyushu, Japan), one M.m. castaneus male from Asia (Chonburi, Thailand), and three $M$. domesticus males (Poschiavo, Switzerland; Tirano, Italy; and Erfoud, Morocco). Only a single base pair substitution was found among these 10 samples; the samples of M.m. molossinus and $\mathrm{C} 57 \mathrm{BL} / 6 \mathrm{~J}$ contain a thymine in place of cytosine at nucleotide position 285, resulting in a nonconservative amino acid change (threonine to isoleucine) in the putative open reading frame.

\section{Discussion}

We identified six types of Y Chrs among the 39 inbred mouse strains examined, based on the combined results of RFLP analyses with pYB10 and three nonecotropic virus probes (Table 1). These six types include three Y Chrs of Asian M. musculus origin and three of $M$. domesticus origin. Our data both corroborate and augment earlier findings in which two types of Y Chrs were identified in inbred mice (Lamar and Palmer 1984; Bishop et al. 1985; Nishioka and Lamothe 1986; Nishioka 1987).

The Asian origin of the M. musculus Y Chr found in most "old" inbred mouse strains is supported by the RFLP analysis with $Y B 10$ and the analysis with the male sex-determining gene $S r y$. The 221-bp sequence of $S r y$ from Asian M. musculus (M.m. molossinus) is 
Table 2. Presence and absence of YB10 restriction fragments in inbred strains of mice and representative samples from $M u s$ musculus and $M$. domesticus. The presence of a specific size restriction fragment is given by an "X," and the absence of a restriction fragment is given by a " - ."

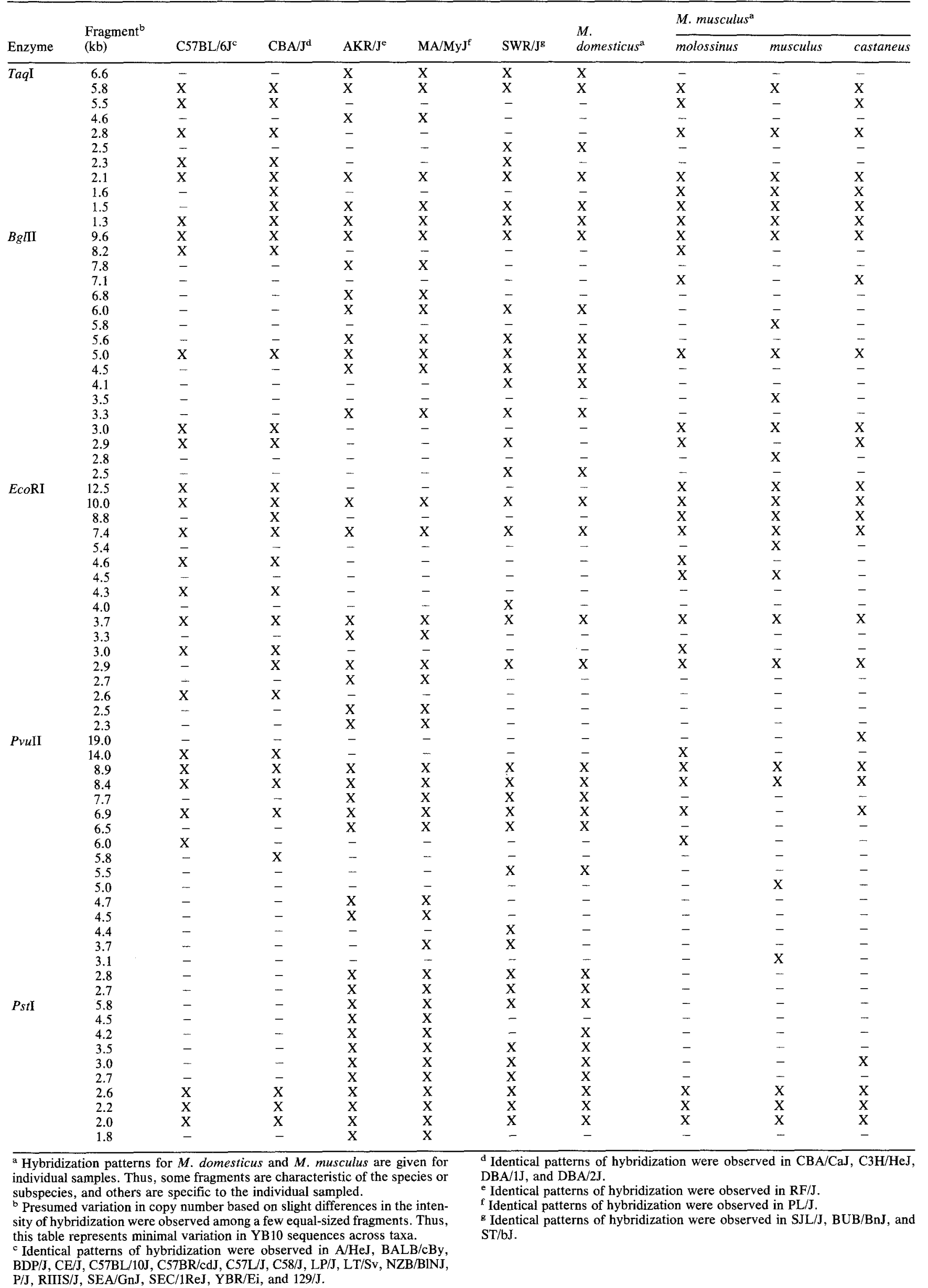




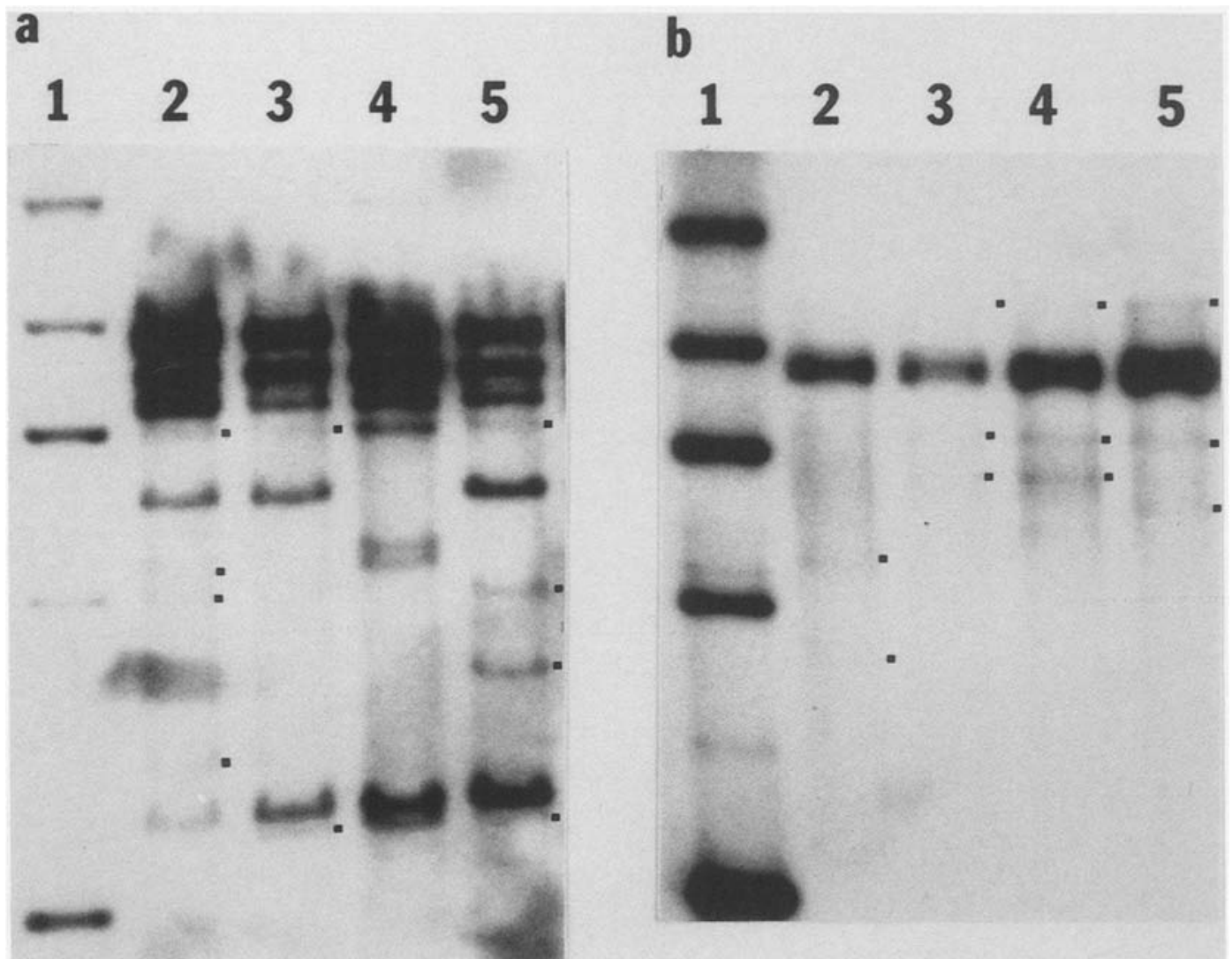

Fig. 1. Two autoradiographs of male genomic DNA cut with $P v u I I$ and probed with pYB10. (a) Lane 1, $\lambda$ HindIII size standard; lane 2, $M$. domesticus from Heidelberg, Germany; lane 3, $M$. domesticus from Tübingen, Germany; lane 4, RF/J; and lane 5, ST/bJ. (b) Lane

identical to that of $\mathrm{C} 57 \mathrm{BL} / 6 \mathrm{~J}$ and 129 , the latter published by Gubbay et al. (1990), but differs from homologous sequences in other subspecies of $M$. musculus and $M$. domesticus by a single base pair change at position 285. Because both YB10 and Sry are from the region of the $\mathrm{Y}$ Chr that does not recombine with the $\mathrm{X} \mathrm{Chr}$, we hypothesize that all inbred strains with a C57BL/6J and 129 YB10 hybridization pattern also will carry an Sry sequence of Asian origin.

Our data support the view that mice from Japan contributed to the formation of the "old" inbred strains by way of the mouse fanciers' trade (Keeler 1931; Potter 1978; Festing and Lovell 1981). The presence of M.m. castaneus as well as M.m. molossinus alleles in inbred mouse strains (Blank et al. 1986) can be explained if the founding males of most of the inbred strains were derived from Japanese M.m. molossinus, which is actually a mixture of Asian M.m. musculus, M.m. castaneus, and $M$. domesticus genomes (Yonekawa et al. 1986, 1988; Bonhomme et al. 1989).

Our data also are in accord with historical records documenting the establishment of many of the inbred strains (reviewed in Morse 1981). For example, one type of Asian $M$. musculus Y Chr is shared by four inbred strains that are known to be related through paternal ancestry. These include CBA, C3H, DBA/1J,
1, $\lambda$ HindIII size standard; lane 2, M.m. musculus from Vejumbro, Germany; lane 3, M.m. molossinus from Japan; lane 4, LT/Sv; and lane 5, DBA/2J. Low copy number fragments are identified by closed circles.

and DBA/2J (Table 1). Strong (1942) mated a male from "stock D", the progenitor strain of DBA/1 and $\mathrm{DBA} / 2$, to a female from "stock $\mathrm{A}$ " to produce "stocks" that ultimately gave rise to CBA and C3H inbred strains. A second type of Asian M. musculus Y Chr is shared by 20 of the inbred strains examined, including C57BL/6, C57BL/10, C57BR, C57L, and C58. The progenitor stocks to C57BL, C57BR, C57L, and $\mathrm{C} 58$ are known to be related through paternal ancestry, because a single male (mouse \#52) was mated to two different females (\#57 and \#58) to produce the C57 and C58 lineages, respectively (Little and Bagg 1924). The observation that a large number of inbred strains carry the C57BL-type Y Chr may reflect the fact that these strains are related through paternal ancestry, because the progenitors of many inbred strains, including C57BL, can be traced back to A.E.C. Lathrop, a mouse fancier from Granby, Massachusetts (Morse 1981).

Our data should help to clarify the origin of inbred strains for which there are no historical records. For example, SWR/J and $\mathrm{SJL} / \mathrm{J}$, which share one type of $M$. domesticus Y Chr, are derived from the so-called "Swiss" mice developed at the Rockefeller Institute by C. Lynch and descended from a Pasteur Institute stock (Lynch 1969). The Y Chrs of SWR/J and SJL/J, as well as $\mathrm{BUB} / \mathrm{BnJ}$ and $\mathrm{ST} / \mathrm{bJ}$, are most closely re- 


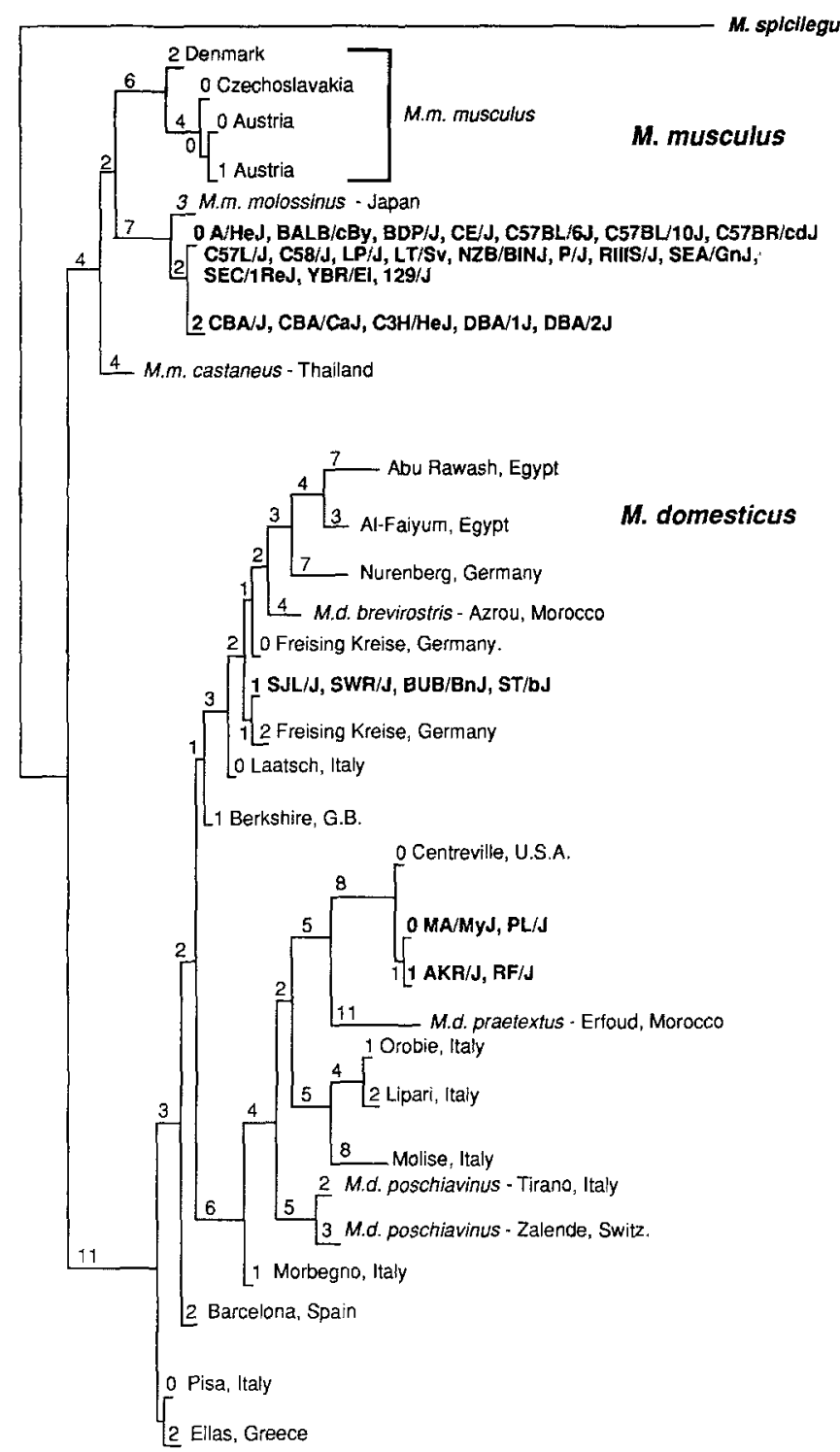

Fig. 2. An evolutionary tree constructed by a phylogenetic analysis by use of parsimony. This tree is one of 25 most parsimonious trees found in a heuristic search. The outgroup is $M$. spicilegus (also referred to as $M$. hortulanus). The length of the tree is 196 steps. The consistency index, a measure of the amount of homoplasy in the data, is $\mathbf{0 . 6 1 2}$. The number of characters (restriction fragments) that determine the length of each horizontal branch is given. Exact collecting localities for all samples are given in Tucker and co-workers (1989). Samples given subspecies designations are indicated.

lated to the $\mathrm{Y}$ Chrs of $M$. domesticus from western Europe, suggesting that the paternal ancestors for these inbred strains were $M$. domesticus from western Europe. The two other types of $M$. domesticus Y Chrs found among four inbred strains, one in MA/MyJ and $\mathrm{PL} / \mathrm{J}$ and the second in AKR/J and RF/J, are very similar to each other and are most closely related to a $Y$ Chr found in $M$. domesticus mice collected in Maryland, suggesting that the paternal ancestors for these strains were $M$. domesticus whose ancestors " $m$ igrated" to the eastern United States. Although RF has been traced to a "Rockefeller Institute" stock (Morse 1981), Lynch (1969) states that RF was not derived from the "Swiss" mice, but rather from another "Rockefeller Institute" stock developed in the United States. Our Y Chr data support her contention. It is interesting that $A K R / J$ and $R F / J$, which have identical YB10 hybridization patterns, were both developed by Jacob Furth (Morse 1981). The close relationship of AKR and RF has recently been supported in phylogenetic analyses of other nuclear genes (Atchley and Fitch 1991).

Many of the inbred strains examined in this study contain $M$. domesticus-derived mtDNA (Yonekawa et al. 1980, 1982; Ferris et al. 1982, 1983a), but none of the old inbred strains examined to date carry Asian $M$. musculus-derived mtDNA. This is a surprising finding in light of the preponderance of Asian $M$. musculus $\mathrm{Y}$ Chrs among the inbred strains examined. It is conceivable that early in the development of European and English fancy mice, crosses were made between Japanese fancy mice of $M . m$. molossinus origin and $M$. domesticus mice of western European origin. Possibly, only crosses between female $M$. domesticus and male M.m. molossinus produced fertile offspring. As a consequence, European and English fancy mice acquired $M$. domesticus mtDNA and an M.m. molossinus Y Chr. Presumably, these mice became part of the American mouse fanciers' trade and contributed to the formation of the "old" inbred strains. Indeed, records indicate that Lathrop imported fancy mice from both England and western Europe (Lathrop and Loeb 1915). In some cases, fancy mice of pure M.m. molossinus origin may have been imported from Europe and subsequently crossed with wild $M$. domesticus from North America.

Finally, the presence of $M$. domesticus mtDNA and Asian M. musculus Y Chrs in most of the inbred strains examined is evidence that many inbred strains of the laboratory mouse are composed of a mixture of two, or possibly three (including M.m. castaneus), distinct genomes. As a consequence, inbred mouse strains should not be considered to be of $M$. domesticus or of $M$. musculus origin. Recently, Artzt and coworkers (1991) have suggested that all inbred mice be regarded by the scientific name Mus laboratorius. This is not appropriate from the standpoint of zoological classification because inbred mice do not constitute a single species characterized by a distinct set of shared derived traits. Rather, inbred mouse strains should be identified by their strain names and simply considered to be of a hybrid $M$. musculus $\times$ domesticus origin or possibly of a hybrid $M$. musculus $\times$ domesticus $\times$ castaneus origin. Furthermore, the use of laboratorius violates the standards set forth in Article 11 of the International Code of Zoological Nomenclature adopted by the General Assembly of the International Union of Biological Sciences (1985).

Acknowledgments. We gratefully acknowledge M. Potter (National Cancer Institute contract N01-CB-71085) for providing frozen organs from various stocks and strains of wild mice, and R.D. Sage for providing frozen organs from a number of captured wild mice. We thank R.L. Honeycutt and W.C. Wheeler for assistance in running 
the phylogenetic analyses and for many helpful discussions concerning the phylogenetic data. We also thank J. Nadeau and T. King for reviewing the manuscript. This publication was supported by grants GM20919 (E.M. Eicher) and HD07065 (The Jackson Laboratory) from the National Institutes of Health and BSR-9009806 (P.K. Tucker) from the National Science Foundation.

\section{References}

Allard, M.W., Ellsworth, D.L., and Honeycutt, R.L.: The production of single-stranded DNA suitable for sequencing using the polymerase chain reaction. Biotechniques 10:24-26, 1991.

Altschul, S.F. and Ericson, B.W.: Optimal sequence alignment using affine gap. Bull Math Biol 48: 603-616, 1986.

Artzt, K., Barlow, D., Dove, W.F., Fischer-Lindahl, K., Klein, J., Lyon, M.F., and Silver, L.M.: Maps of mouse Chromosome 17: first report. Mammalian Genome 1: 5-29, 1991.

Atchley, W.R. and Fitch, W.M.: Gene trees and the origins of inbred strains of mice. Science 254: 554-558, 1991.

Bishop, C.E., Boursot, P., Baron, B., Bonhomme, F., and Hatat, D.: Most classical Mus musculus laboratory mouse strains carry a Mus musculus musculus Y chromosome. Nature 315: 70-73, 1985.

Blank, R.D., Campbell, G.R., and D'Eustachio, P.: Possible derivation of the laboratory mouse genome from multiple wild Mus species. Genetics 114: 1257-1269, 1986.

Bonhomme, F.: Evolutionary relationships in the genus Mus. Curr Top Microbiol Immunol 127: 19-34, 1986.

Bonhomme, F., Britton-Davidian, J., Thaler, L., Chapman, V.M., Moriwaki, K., Nevo, E., and Thaler, L.: Biochemical diversity and evolution in the genus Mus. Biochem Genet 22: 275-303, 1986.

Bonhomme, F., Miyashita, N., Boursot, P., Catalan, J., and Moriwaki, K.: Genetical variation and polyphyletic origin in Japanese Mus musculus. Heredity 63: 299-308, 1989.

Bosselman, R.A., van Straaten, F., Van Beveren, C., Verma, I.M., and Vogl, M.: Analysis of the env gene of a molecularly cloned and biologically active Moloney mink cell focus-forming proviral DNA. J Virol 44: 19-31, 1982.

Buckler, C.E., Hoggan, M.D., Chan, H.W., Sears, J.F., Khan, A.S., Moore, J.L., Hartley, J.W., Rowe, W.P., and Martin, M.A.: Cloning and characterization of an envelope-specific probe from xenotropic murine leukemia proviral DNA. $J$ Virol $41: 228$ 236, 1982.

Eicher, E.M., Hutchison, K.W., Phillips, S.J., Tucker, P.K., and Lee, B.K.: A repeated segment on the mouse $Y$ chromosome is composed of retroviral-related, $\mathrm{Y}$-enriched, and $\mathrm{Y}$-specific sequences. Genetics 122: 181-192, 1989.

Ferris, S.D., Sage, R.D., and Wilson, A.C.: Evidence from mtDNA sequences that common laboratory strains of inbred mice are descended from a single female. Nature 295: 163-165, 1982.

Ferris, S.D., Sage, R.D., Prager, E.M., Ritte, U., and Wilson, A.C.: Mitochondrial DNA evolution in mice. Genetics 105: 681-721, $1983 a$.

Ferris, S.D., Sage, R.D., Huang, C.-M., Nielsen, J.T., Ritte, U., and Wilson, A.C.: Flow of mitochondrial DNA across a species boundary. Proc Natl Acad Sci USA 80: 2290-2294, 1983 b.

Festing, M.F.W. and Lovell, D.P.: Domestication and development of the mouse as a laboratory animal. Symp Zool Soc Lond 47: 43-62, 1981.

Gubbay, J., Collignon, J., Koopman, P., Capel, B., Economou, A., Munsterberg, A., Vivian, N., Goodfellow, P., and Lovell-Badge, R.: A gene mapping to the sex-determining region of the mouse $Y$ chromosome is a member of a novel family of embryonically expressed genes. Nature 346: 245-250, 1990.

Hunt, W.G. and Selander, R.K.: Biochemical genetics of hybridisation in European mice. Heredity 31: 11-33, 1973.

International Code of Zoological Nomenclature, University of California Press, Berkeley, 1985.
Keeler, C.E.: The Laboratory Mouse, pp. 1-81, Harvard University Press, Cambridge, 1931.

Lamar, E.E. and Palmer, E.: Y-encoded, species-specific DNA in mice: evidence that the $\mathrm{Y}$ chromosome exists in two polymorphic forms in inbred strains. Cell 37: 171-177, 1984.

Lathrop, A.E.C. and Loeb, L.: Further investigations on the origin of tumors in mice. $J$ Exp Med 22: 646-673, 1915.

Little, C.C. and Bagg, H.J.: The occurrence of four inheritable morphological variations in mice and their possible relation to treatment with X-rays. J Exp Zool 41: 45-91, 1924.

Lynch, C.J.: The so-called Swiss mouse. Lab Animal Care 19:214 220, 1969.

Maniatis, T., Fritsch, E.F., and Sambrook, J.: Molecular Cloning: a Laboratory Manual. Cold Spring Harbor Laboratory Press, Cold Spring Harbor, N.Y., 1982.

Moriwaki, K., Miyashita, N., Suzuki, H., Kurihara, Y., and Yonekawa, H.: Genetic features of major geographical isolates of Mus musculus. Curr Top Microbiol Immunol 127: 55-61, 1986.

Morse, H.C. III: Introduction. In H.C. Morse, III (ed.): Origins of Inbred Mice, pp. 3-21, Academic Press, New York, 1978.

Morse, H.C. III: The laboratory mouse-a historical perspective. In H.L. Foster, J.D. Small, and J.G. Fox (eds.); The Mouse in Biochemical Research Vol. I., pp. 1-16, Academic Press, New York, 1981.

Nishioka, Y.: Y-chromosomal DNA polymorphism in mouse inbred strains. Genet Res 50: 69-72, 1987.

Nishioka, Y. and Lamothe, E.: Isolation and characterization of a mouse $\mathrm{Y}$ chromosomal repetitive sequence. Genetics 113: 417432, 1986.

O'Neill, R.R., Khan, A.S., Hoggan, M.D., Hartley, J.W., Martin, M.A., and Repaske, R.: Specific hybridization probes demonstrate more MCF than xenotropic MuLV env related sequences in DNAs from inbred laboratory mice. $J$ Virol 58: 359-366, 1986.

Potter, M.: Comments on the relationship of inbred strains to the genus Mus. In H.C. Morse, III (ed.); Origins of Inbred Mice, pp. 497-509, Academic Press, New York, 1978.

Sage, R.D., Whitney III, J.B., and Wilson, A.C.: Genetic analysis of a hybrid zone between domesticus and musculus mice (Mus musculus complex): hemoglobin polymorphisms. Curr Top Microbiol Immunol 127: 75-85, 1986a.

Sage, R.D., Heyneman, D., Lim, K.-C., and Wilson, A.C.: Wormy mice in a hybrid zone. Nature 324: 60-63, 1986b.

Saiki, R.K., Scharf, S., Faloona, F., Mullis, K.B., Horn, G.T., Erlich, A., and Arnheim, N.: Enzymatic amplification of B-globin genomic sequences and restriction site analysis for diagnosis of sickle cell anemia. Science 230: 1350-1354, 1985.

Sanger, F., Nicklen, S., and Coulson, A.R.: DNA sequencing with chain terminating inhibitors. Proc Natl Acad Sci USA 74: 54635467, 1977.

Strong, L.C.: The origin of some inbred mice. Cancer Res 2: 531$539,1942$.

Swofford, D.L.: PAUP version 2.4, Illinois Natural History Survey, Champaign, Ill., 1985.

Tucker, P.K., Lee, B.K., and Eicher, E.M.: Y chromosome evolution in the subgenus Mus (genus Mus). Genetics 122: 169-179, 1989.

Tucker, P.K., Sage, R.D., Warner, J.H., Wilson, A.C., and Eicher, E.M.: Abrupt cline for sex chromosomes in a hybrid zone between two species of mice. Evolution, in press, 1992.

Vanlerberghe, F., Dod, B., Boursot, P., Bellis, M., and Bonhomme, F.: Absence of Y-chromosome introgression across the hybrid zone between Mus musculus domesticus and Mus musculus musculus. Genet Res 48: 191-197, 1986.

Vanlerberghe, F., Boursot, P., Nielsen, J.T., and Bonhomme, F.: A steep cline for mitochondrial DNA in Danish mice. Genet Res 52: 185-193, 1988a.

Vanlerberghe, F., Boursot, P., Catalan, J., Gerasimov, S., Bonhomme, F., Botev, B.A., and Thaler, L.: Analyse genetique de la zone d'hybridation entre les deux sous-especes de souris Mus musculus domesticus et Mus musculus musculus en Bulgarie. Genome 30: 427-437, 1988b.

Yonekawa, H., Moriwaki, K., Gotoh, O., Wantanabe, J., Hayashi, J.-I., Miyashita, N., Petras, M.L., and Tagashira, Y.: Relation- 
ship between laboratory mice and the subspecies Mus musculus domesticus based on restriction endonuclease cleavage patterns of mitochondrial DNA. Jpn J Genet 55: 289-296, 1980.

Yonekawa, H., Moriwaki, K., Gotoh, O., Miyashita, N., Migita, S., Bonhomme, F., Hjorth, J.P., Petras, M.L., and Tagashira, Y.: Origins of laboratory mice deduced from restriction patterns of mitochondrial DNA. Differentiation 22: 222-226, 1982.

Yonekawa, H., Gotoh, O., Tagashira, Y., Matsushima, Y., Shi,
L.-I., Cho, W.S., Miyashita, N., and Moriwaki, K.: A hybrid origin of Japanese mice "Mus musculus molossinus." Curr Top Microbiol Immunol 127: 62-67, 1986.

Yonekawa, H., Moriwaki, K., Gotoh, O., Miyashita, N., Matsushima, Y., Liming, S., Cho, W.S., Xiao-Lan, Z., and Tagashira, Y.: Hybrid origin of Japanese mice: "Mus musculus molossinus": evidence from restriction analysis of mitochondrial DNA. Mol Biol Evol 5: 63-78, 1988. 